\title{
SOLUSI PENANGANAN PENUMPUKAN PENUMPANG STASIUN DURI AKIBAT PENGOPERASIAN KA BANDARA
}

\author{
Ir. Bambang Drajat, MM \\ Dosen Sttd \\ J1. Raya Setu No. 89, Bekasi \\ Telp./Fax : (021) 8254640
}

\author{
Nomin, M.Pd \\ Dosen STTD \\ Jl. Raya Setu No. 89, Bekasi \\ Telp./Fax : (021) 8254640
}

\author{
Eka Arista, M.Sc \\ Dosen STTD \\ Jl. Raya Setu No. 89, Bekasi \\ Telp./Fax : (021) 8254640
}

\author{
Ir. J.R.C Hosang, M.Sc \\ Dosen STTD \\ Jl. Raya Setu No. 89, Bekasi \\ Telp./Fax : (021) 8254640
}

\author{
Utut Widyanto, M.Sc \\ Dosen STTD \\ J1. Raya Setu No. 89, Bekasi \\ Telp./Fax : (021) 8254640
}

\begin{abstract}
At this time the airport train operating pattern has a frequency of 18 trains going back and forth per day, and in the process of operation the airport train transits at Duri station to transfer drivers because the Duri station layout track does not allow airport trains to run directly to the station between Batu Ceper and the end station Airport Station. From the transit process at Duri Station, there is a problem with the accumulation of Commuter Line train passengers, because both Commuter Line passengers who aim to Angke station and Tanah Abang station when they want to change trains must walk from the platform at the end to the platform which is well located middle or other end. In addition to the problem of passenger accumulation, there is also a problem with the platform width to accommodate passengers while waiting for the train, because besides there are shortcomings in terms of passenger comfort, the passenger safety side is less well maintained and travel frequency decreases.
\end{abstract}

Keywords: Airport trains, frequency of trips, solutions

\section{ABSTRAKSI}

Pada saat ini kereta bandara pola pengoperasiannya memiliki frekuensi 18 kereta pulang pergi perharinya, dan dalam proses operasinya kereta bandara ini transit di stasiun Duri untuk melakukan perpindahan masinis dikarenakan track layout stasiun Duri tidak memungkinkan untuk kereta bandara berjalan langsung menuju stasiun antara Batu Ceper maupun stasiun akhir Stasiun Bandara. Dari proses transit di stasiun Duri ini terdapat masalah penumpukan penumpang kereta api Commuter Line, karena para penumpang Commuter Line baik yang bertujuan ke stasiun Angke maupun stasiun Tanah Abang ketika ingin berpindah kereta harus berjalan dari peron yang berada di ujung menuju ke peron yang baik 
berada di tengah maupun diujung yang lain. Selain masalah penumpukan penumpang juga terdapat masalah lebar peron guna menampung penumpang ketika menunggu kereta, karena selain ada kekurangan dari segi kenyamanan penumpang, sisi keselamatan penumpang pun kurang terjaga serta frekuensi perjalanan berkurang sehingga waku tunggu kereta bertambah lama.

\section{Kata Kunci : Kereta api Bandara, Frekuensi perjalanan, solusi}

\section{PENDAHULUAN}

\section{Latar Belakang}

Di wilayah Jabodetabek, transportasi kereta api merupakan moda transportasi favorit masyarakat guna melakukan perjalanan utamanya ketika jam sibuk pagi maupun sore. Dalam system perkeretaapian terdapat interaksi antara sarana dan prasarana, prasarana perkeretaapian terdiri dari stasiun, jalan rel, dan fasilitas operasi kereta api seperti persinyalan, telekomunikasi dan pelistrikan. Karakteristik operasional kereta api dimana kereta api memulai dan mengakhiri perjalanan di stasiun mendorong peran stasiun tidak hanya sebagai terminal pemberangkatan namun juga bisa menjadi tempat untuk para pengguna jasa kereta api berinteraksi dan menjadi tempat integrasi moda. Semenjak pengoperasiannya, Kereta Bandara Soetta cukup menarik minat para pengguna jasa transportasi yang bertujuan ke bandara Soetta sebagai salah satu alternative moda. Namun pengoperasian kereta bandara ini berdampak kepada pengoperasian kereta Commuter Line yang berjalan saat ini. Pada saat ini kereta bandara pola pengoperasiannya memiliki frekuensi 18 kereta pulang pergi perharinya, dan dalam proses operasinya kereta bandara ini transit di stasiun Duri untuk melakukan perpindahan masinis dikarenakan track layout stasiun Duri tidak memungkinkan untuk kereta bandara berjalan langsung menuju stasiun antara Batu Ceper maupun stasiun akhir Stasiun Bandara. Dari proses transit di stasiun Duri ini terdapat masalah penumpukan penumpang kereta api Commuter Line, karena para penumpang Commuter Line baik yang bertujuan ke stasiun Angke maupun stasiun Tanah Abang ketika ingin berpindah kereta harus berjalan dari peron yang berada di ujung menuju ke peron yang baik berada di tengah maupun diujung yang lain. 


\section{A. Rumusan Masalah}

Dalam asumsi umum, masalah biasanya selalu diartikan suatu kondisi ketidaksesuaian antara apa yang diinginkan dengan kenyataan yang diperoleh. Masalah merupakan suatu kesulitan yang mengharuskan setiap orang untuk berusaha mencari solusi untuk mengatasi atau memecahkannya. Berdasarkan asumsi tersebut yang telah dikemukakan, maka ada beberapa hal yang menjadi pertanyaan dalam penelitian ini, yaitu :

1. Bagaimana solusi pengurangan penumpukan penumpang di stasiun Duri akibat pengoperasian kereta bandara?

2. Bagaimana meminimalisir perpindahan penumpang dari peron satu ke peron yang lain ?

3. Bagaimana kebutuhan emplasement terkait penumpukan jumlah penumpang di stasiun Duri ?

\section{GAMBARAN UMUM}

\section{A. Wilayah Operasi Commuter Line}

Dalam wilayah operasi kereta api DAOP I Jabodetabek saat ini beroperasi kereta api komuter (loop line) dan KA Bandara, kereta api jarak menengah dan jauh. Jumlah penumpang KA Jabodetabek semakin bertambah, berikut data perkiraan jumlah penumpang KA Jabodetabek.

Tabel Perkiraan Jumlah Penumpang KA Jabodetabek

REKAPITULASI PRAKIRAAN JUMLAH PNP DAN SARANA TAHUN 2014 SAMPAI DENGAN TAHUN 2035

\begin{tabular}{|c|c|c|c|c|c|c|c|c|c|c|c|}
\hline \multirow{8}{*}{$\begin{array}{l}\text { H } \\
\text { E } \\
\text { A } \\
\text { D } \\
\text { W } \\
\text { A } \\
\text { Y }\end{array}$} & LINTAS I TAHUN & 2014 & 2015 & 2016 & 2017 & 2018 & 2019 & 2020 & 2025 & 2030 & 2035 \\
\hline & TENGAH & 5.6 & 5.3 & 5.0 & 5.0 & 4.6 & 4.3 & 3.9 & 2.5 & 1.9 & 1.9 \\
\hline & BOGOR & 5.9 & 5.3 & 4.7 & 5.0 & 4.6 & 4.3 & 3.9 & 2.5 & 1.9 & 1.9 \\
\hline & BEKASI & 12.0 & 12.0 & 12.0 & 9.2 & 8.0 & 7.2 & 6.1 & 4.3 & 2.9 & 2.0 \\
\hline & SERPONG & 13.8 & 12.4 & 11.3 & 10.5 & 8.0 & 7.2 & 6.1 & 4.3 & 2.9 & 2.0 \\
\hline & TANGERANG & 18.0 & 17.0 & 16.0 & 14.0 & 8.7 & 7.5 & 7.6 & 4.5 & 3.8 & 2.3 \\
\hline & LINGKAR & 13.3 & 11.9 & 10.4 & 9.2 & 12.0 & 12.0 & 10.0 & 5.5 & 5.0 & 4.0 \\
\hline & TANJUNGRPIUK & 30.0 & 25.0 & 20.0 & 15.0 & 8.0 & 7.2 & 6.1 & 5.0 & 4.0 & 4.0 \\
\hline \multicolumn{2}{|c|}{ RATA-RATA HEADWAY } & 16 & 15 & 12 & 11 & 9 & 7.2 & 6.1 & 5.7 & 3.8 & 3.1 \\
\hline \multicolumn{2}{|c|}{ JML PNP PER HARI (ribuan) } & 605 & 655 & 877 & 953 & 1,172 & 1,287 & 1,437 & 2,190 & 2,822 & 3,469 \\
\hline \multicolumn{2}{|c|}{ KEBUT SARANA OPERASI (SO) } & 591 & 605 & 754 & 962 & 1,108 & 1,217 & 1,344 & 2,069 & 2,738 & 3,452 \\
\hline
\end{tabular}


Pada tahun 2018 telah beroperasi kereta api Bandara Soekarno Hatta (KA BASOETA) yang rencananya akan dioperasikan sebanyak $44 \mathrm{KA}$ dan untuk saat ini 9 KA bandara telah

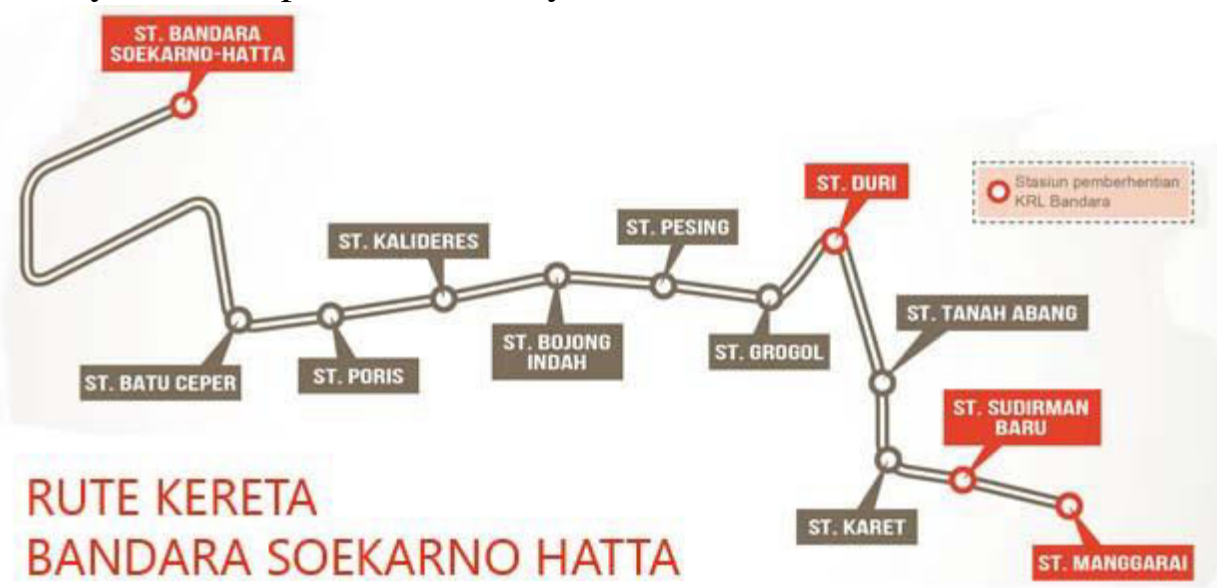

beroperasi. Adapun jalur KA BASOETA dan KA Komuter DAOP I Jabodetabek dapat dilihat pada Gambar 3.1 dan 3.2.

\section{B. Stasiun Duri}

Stasiun Duri (DU) merupakan stasiun kereta api kelas besar yang terletak di jalan Kali Anyer, dan termasuk ke dalam Daerah Operasi I Jakarta. Stasiun ini mempunyai jalur cabang menuju Tangerang.Stasiun ini memiliki lima jalur kereta api. Jalur 1 digunakan sebagai sepur belok untuk KRL Yellow Line arah Angke \& Jatinegara, sedangkan jalur 2 merupakan sepur lurus arah Tanahabang, Depok, Nambo \& Bogor. Jalur 3 dan 4 merupakan langsir untuk KRL Railink Basoetta arah Sudirman Baru \& Soekarno Hatta dan Jalur 5 merupakan jalur terminus untuk KRL Brown Line arah Tageranag.

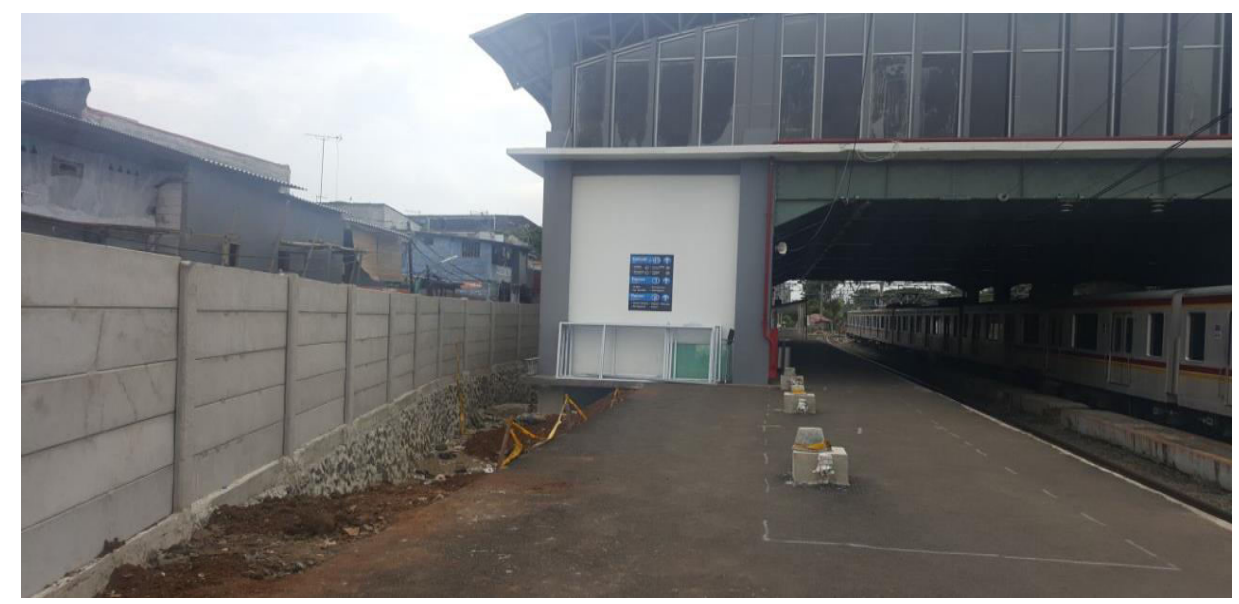




\section{ANALISIS DAN PEMBAHASAN}

\section{A. Kapasitas Kereta Api}

Hasil dari survey diperoleh bahwa lintas Manggarai - Tanah Abang masih memiliki kapasitas yang tersedia sebanyak 75 Kereta Api dan Lintas Tanah Abang - Duri masi memiliki kapasitas yang tersedia sebanyak 126 Kereta Api.

Berdasarkan perhitungan kapasitas pada peak pagi, diperoleh 36 KA namum jumlah pada saat peak pagi (pukul 05.00 WIB sampai dengan pukul 09.00 WIB) sebanyak 40 Kereta api. Sehingga terjadi kelebihan frekuensi terhadap kapasitas pada saat peak pagi sebanyak $4 \mathrm{KA}$, sehingga diperlukan penyesuaian frekuensi KRL Tangerang line pada saat peak pagi semula 22 KRL menjadi 18 KRL.

Kapasitas angkut KRL Tangerang line pada saat peak pagi sebanyak :

Kapasitas angkut $=8 \mathrm{KA} /$ rangkaian $\times 22 \mathrm{KRL}$

$$
=176 \text { kereta }
$$

Dengan adanya perubahan frekuensi, maka diperlukan penyesuaian panjang rangkaian menjadi :

Jumlah rangkaian minimum $=176$ kereta $: 18 \mathrm{KRL}$

$$
=10 \mathrm{kereta} / \text { rangkaian }
$$

Jumlah rangkaian minimum adalah 10 kereta dan maksimum 12 kereta yang dapat digunakan.

\section{B. Jumlah Penumpang Stasiun Duri}

Data hasil survey primer jumlah penumpang, untuk Tap in dan Tap out di stasiun duri rata rata 20 ribu orang per hari, sedangkan penumpang transit di stasiun duri rata rata 35 ribu orang per hari di stasiun tanah abang tap in dan tap out rata rata 38 ribu orang per hari, sedangkan penumpang transit di stasiun tanah abang rata rata 60 ribu per hari. 


\begin{tabular}{|c|c|c|c|}
\hline No & Tanggal & Gate in & Gate Out \\
\hline 1 & 24 September 2018 & 12.164 & 12.105 \\
\hline 2 & 25 September 2018 & 9.853 & 9.625 \\
\hline 3 & 26 September 2018 & 9.285 & 9.811 \\
\hline 4 & 27 September 2018 & 8.337 & 9.874 \\
\hline 5 & 28 September 2018 & 9.853 & 9.280 \\
\hline
\end{tabular}

Pergerakan penumpang terbanyak pada pukul 08.00 WIB dan pukul 17.00 sampai dengan 18.00 WIB. Dan relasi terbanyak arah tanah abang - Ma nggarai dan Tanah Abang Serpong - Maja - Ragkasbitung. Dan waktu tunggu rata rata penumpang di peron jalur 2 dan 3 serta jalur 5 dan 6 adalah 10 sampai dengan 15 menit sehingga mengakibatkan penumpukan penumpang.

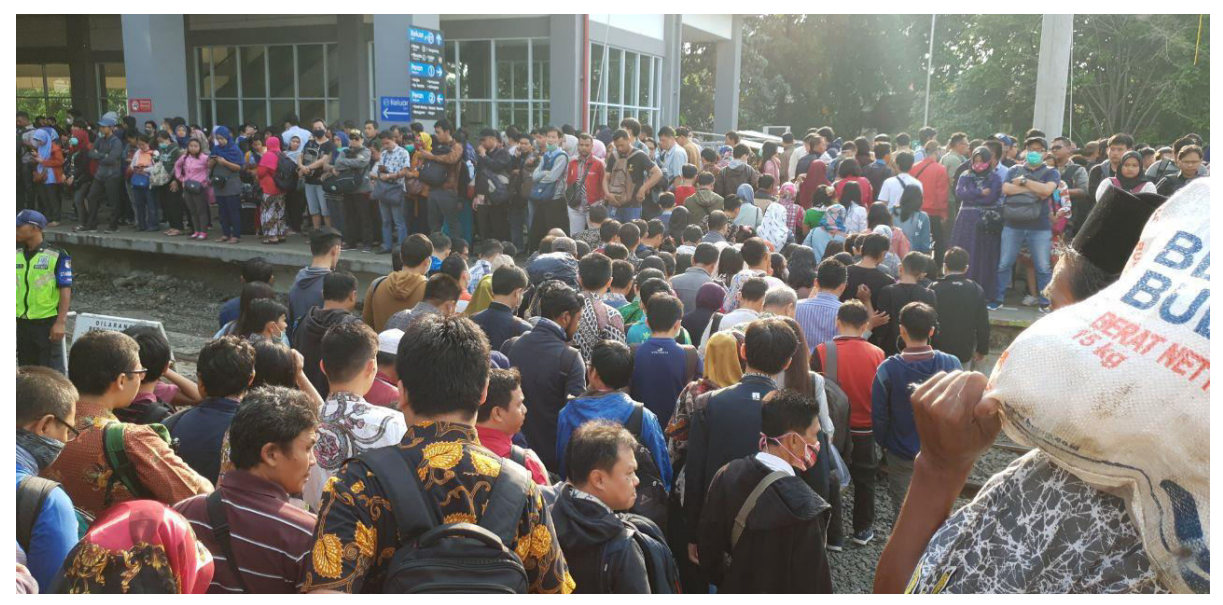

Gambar Kondisi Penumpukan Penumpang St.Duri

\section{Rencana Emplasement Stasiun Duri}

Emplasement stasiun dipersyaratkan mampu melayani operasi perjalanan kereta api sekurang kurangnya berkaitan dengan 
1. Jumlah jalur kereta api memenuhi kebutuhan operasi sesuai dengan junlah kereta api yang dilayani secara optimal. Hal ini berkaitan dengan perhitungan kapasitas stasiun, yang sangat erat kaitannya dengan perhitungan Kapasitas lintas

2. Panjang jalan rel efektif merupakan panjanng jalan rel yang ditentukan berdasarkan rangkaian kereta api terpanjang yang ditambah minimal 20 meter. Hal ini diperlukan untk memastikan rangkaian kereta api berada dalam batas patok bebas

3. Tata letak jalan rel disesuaikan dengan pola operasi yang dilayani.

Dari hasil survey lapangan, stasiun duri memiliki lahan yang terbatas dan terdapat rumah serta jalan warga di dalam ROW . Dengan kondisi terjadinya penumpukan di stasiun duri, maka lahan yang dipakai warga seluas $10 \mathrm{~m}$ x $350 \mathrm{~m}$ bisa ditambahkan 1 jalur siding.

Panjang jalur siding $=$ panjang KRL $x$ jumlah/rangkaian + panjang overlap

$$
\begin{aligned}
& =20 \mathrm{~m} \times 12 \text { kereta }+20 \mathrm{~m} \\
& =260 \text { meter }
\end{aligned}
$$

jadi panjang jalur siding minimal 260 meter. Dalam hal ini jalur siding yang direncanakan 300 meter dengan melihat kondisi lahan yang masih memungkinkan guna mengatasi penumpukan penumpang. Rencana penambahan jalur siding dapat dilihat di gambar berikut ini.

D. Kebutuhan Pembangunan Jalur Baru

Dengan direncanakan jalur baru maka, kebutuhan prasarana yang direncanakan adalah sebagai berikut :

1. Kebutuhan wesel

Wesel terdiri dari sepasang rel yang ujungnya diruncingkan sehingga dapat melancarkan perpindahan kereta api dari jalur yang satu ke jalur yang lain dengan menggeser bagian rel yang runcing. Jalur siding yang akan dibangun sepanjang 300 meter terletak disebelah kanan jalur $\mathrm{V}$ eksisting, sehingga dibutuhkan 1 wesel kiri 1 : 10 untuk mendukung pengoperasian jalur baru. 


\section{Kebutuhan Rel}

Panjang jalur siding yang direncanakan sepanjang 300 meter. Jenis rel yang akan digunakan adalah R54, 1 batang R54 memiliki panjang 25 meter, sehingga untuk membangun 300 meter diperlukan 24 batang rel jenis R54.

3. Kebutuhan bantalan

Bantalan rel adalah landasan tempat rel bertumpu dan diikat dengan penambat rel, oleh karena itu harus cukup kuat untuk menahan beban kereta api yang berjalan di atas rel. Bantalan dipasang melintang rel pada jarak antara bantalan yang satu dengan lainnya sepanjang 0,6 $\underline{\text { meter. }}$. Dengan panjang jalur siding yang direncanakan sepanjang 300 meter, maka bantalan yang dibutuhkan sebanyak 500 batang bantalan. Bantalan yang dipakai adalah bantalan beton. Bantalan beton dibuat dari beton bertulang prategang, pada bantalan beton juga sekaligus ditempatkan angker penambat. Keunggulan dari bantalan beton adalah daya tahan terhadap cuaca dibanding dengan bantalan kayu

4. Sistem persinyalan

Sistem persinyalan yang dibutuhkan yaitu dengan menggunakan sistem persinyalan SSI stasiun duri. Keunggulan dari sistem SSI yaitu hemat kabel karena menggunakan kabel data untuk interlocking system nya

5. Jaringan LAA

Penambahan jaringan LAA di jalur baru dan LAA dimodifikasi sesuai dengan wesel yang terkait

\section{KESIMPULAN DAN SARAN}

\section{A. Kesimpulan}

1. Dari hasil pembahasan diketahui telah terjadi penumpukan penumpang di stasiun Duri dan solusi penanganan penumpukan tersebut adalah dengan dilakukan penyesuaian frekuensi KRL Tangerang Line pada peak pagi dari yang semula 22 KRL dengan 8 rangkaian menjadi $18 \mathrm{KRL}$ dengan panjang rangkaian KA disesuaikan dari semula 8 rangkaian/kereta menjadi 10-12 rangkaian/kereta.

2. Solusi pengurangan penumpang di stasiun Duri yaitu dengan menambahkan escalator, dan beberapa stasiun antara Duri dan Tagerang dengan menambahkan siding Track. 
3. Cara meminimalisir perpindahan penumpang dari satu peron ke peron yang lain denga semua menggubakan escalator bukan passangger crossing.

4. Kebutuhan emplacement terkait penumpukan jumlah penumpang di stasiun duri yaitu dengan menambahkan 1 peron dan 1 track, yaitu track no 6.

\section{B. Saran}

1. Emplasement stasiun pesing, grogol, kalideres dan duri ditambah jalur baru

2. Untuk penanganan permasalahan perpindahan penumpang dari peron satu ke peron lainnya maka diusulkan agar dibangun satu jalur siding baru dengan panjang minimal 260 meter pada lahan di sekitar stasiun Duri

3. Dengan adanya jalur siding baru maka untuk lebih memperlancar pergerakan naik turun penumpang dan mengatasi masalah penumpukan maka pada jalur siding baru akan ditambahkan juga emplasemen baru dengan lebar 9 meter.

4. Dibuat shortcut di stasiun tanah abang, grogol agar KA bandara tidak harus berhenti di stasiun duri, tanah abang dan manggarai, sehingga jika fasoop loopine sudah berjalan, makan frekuensi KRL dapat bertambah.

5. Hasil pembahasan penelitian ini masih belum mencakup isu lain yang terkait dengan pengoperasian KA Bandara sehingga butuh penelitian lebih lanjut.

6. Dengan keterbatasan waktu serta biaya, fasilitas pendukung serta prasarana yang dibutuhkan dalam pengembangan stasiun Duri belum sepenuhnya dibahas detil sehingga bisa menjadi masukan untuk penelitian lebih lanjut.

7. Dari hasil pembahasan penelitian ini diharapkan dapat menjadi masukan awal pengembangan stsiun Duri kepada instansi yang berwenang. 


\section{DAFTAR PUSTAKA}

Undang-Undang Nomor: 23 tahun 2007 Perkeretaapian

Peraturan Menteri Perhubungan No. 17 Tahun 2018 Pedoman Tata Cara Perhitungan Dan

Penetapan Tarif Angkutan Orang Dengan Kereta Api

PERATURAN MENTERI PERHUBUNGAN NOMOR PM 74 TAHUN 2011 tentang

Penyelenggaraan Kewajiban Pelayanan Publik Angkutan Orang Dengan Kereta Api

Pelayanan Kelas Ekonomi

Peraturan Menteri Perhubungan Nomor Pm 43 Tahun Tentang Rencana Induk

Perkeretaapian Nasional

Peraturan Menteri Perhubungan Nomor Pm 36 Tahun 2011 Tentang Perpotongan

Dan/Atau ___Persinggungan Antara Jalur Kereta Api Dengan Bangunan Lain

Peraturan Menteri Perhubungan Nomor Pm 34 Tahun 2011 Tentang Tata Cara

Perhitungan Dan ___Penetapan Tarif Angkutan Orang Dan Barang Dengan Kereta Api

Peraturan Menteri Perhubungan Nomor Pm 33 Tahun 2011 Tentang Jenis, Kelas Dan

Kegiatan Di Stasiun Kereta Api.

Peraturan Menteri Perhubungan Nomor Pm 31 Tahun 2011 Tentang Standar Dan Tata

Cara ___Pemeriksaan Prasarana Perkeretaapian

Peraturan Pemerintah Republik Indonesia Nomor 81 Tahun 1998 Tentang Lalu Lintas

Dan Angkutan Kereta Api.

Peraturan Pemerintah Republik Indonesia Nomor 69 Tahun 1998 Tentang Prasarana Dan Sarana Kereta Api.

Keputusan Menteri Perhubungan Nomor Km. 8 Tahun 1991 Tentang Organisasi Dan Tata Kerja ___Perusahaan Umum (PERUM) Kereta Api

Anonim, Ballast : Wikipedia diakses pada 26 Mei 2018 pukul 11.00 WIB

PD 10 tentang Jalur dan Bangunan Kereta Api 